\title{
Correlation of Vitamin D and Body Mass Index with Modic Changes in Patients with Non-Specific Low Back Pain in a Sub-Tropical Asian Population
}

\author{
Anoop Mattam ${ }^{1}$, George Sunny ${ }^{2}$ \\ ${ }^{1}$ Department of Orthopaedics, St. John's Medical College, Banglore, India \\ ${ }^{2}$ Department of Radiology, St. John's Medical College, Banglore, India
}

Study Design: Cross-sectional study by non-probability consecutive sampling.

Purpose: The objective of this study was to assess body mass index (BMI) and investigate vitamin D levels in patients with low back pain (LBP) and study a possible relationship with myopathy-related symptoms and Modic changes.

Overview of Literature: LBP is a multifactorial problem and the search for its patho-anatomical causes is ongoing. Modic changes seem to be a cause of back pain but the pathological mechanisms underlying this are not completely defined. Hypovitaminosis $D$ and obesity have also been shown to cause chronic musculoskeletal pain. The relationship between vitamin D deficiency and BMI with Modic changes has not been studied in detail.

Methods: Three hundred and sixteen patients with chronic LBP was selected for the study by non-probability consecutive sampling. The study was conducted over a period of 12 months from January 2014 to December 2014 at St. John's Medical College, Banglore. Questionnaires were provided to the participants and demographic information, symptoms, weight and height were recorded from the study subjects. BMI was calculated. Serum vitamin D level was assessed and Modic changes studied on magnetic resonance imaging. Correlations between vitamin D, BMl and Modic changes were studied using correlation coefficients and odds ratios obtained from logistic regression.

Results: Two hundred and fifty-six out of 316 patients (80\%) had low vitamin D. $83 \%$ of patients with BMl> $25 \mathrm{~kg} / \mathrm{m}^{2}$ had low vitamin $D$ levels as compared to $69 \%$ with $B M l<25 \mathrm{~kg} / \mathrm{m}^{2}$. Statistically significant correlation coefficients were found between vitamin D levels, BMl and Modic changes. Significant association was found between low vitamin D levels and Modic changes (odds ratio 1.75). Conclusions: Vitamin D deficiency and obesity have significant relations with LBP. Low vitamin D levels is associated with Modic changes but whether they represent a subgroup of patients whose low backpain is associated with low vitamin $D$ needs to be further evaluated.

Keywords: Spine; Low back pain; Vitamin D; Modic change; Body mass index

\section{Introduction}

Low back pain involves bone and muscles of the back region and is defined as pain localised in the area below the costal margins and above the inferior gluteal folds [1]. Back pain is multi-factorial in origin [2] and a defini-

Received Apr 20, 2015 Revised Jun 16, 2015 Accepted Jun 16, 2015

Corresponding author: Anoop Mattam

Department of Orthopaedics, St. John's Medical College, Koramangala Banglore, Banglore, Karnataka 560034, India

Tel: +91-78298-24008, Fax: +91-477224-2109, E-mail: mattam.dr@gmail.com 
tive patho-anatomical diagnosis is not possible in $80 \%$ of low back pain patients and is often designated as a nonspecific back pain [3].

Modic changes in the magnetic resonance imaging (MRI) scans have been studied as one among the causes of back pain. Modic et al. [4] defined type 1 changes which are due to inflammation and show hypervascularity of the vertebrae and type 2 changes which are fatty replacement of the bone marrow. Modic changes were seen in more than $40 \%$ of patients with low back pain compared to $6 \%$ of the unaffected normal population [5]. The mechanisms for development of Modic changes are not completely understood. One proposed cause is inflammatory edema due to micro fractures at endplate caused by shear forces as a result of degenerative changes [6]. Also vitamin D deficiency is known to cause musculoskeletal pain [7]. Vitamin D has a role in calcium haemostasis and optimization of muscular and neurological functions. Vitamin D also plays a role in the inflammatory cascade by increasing anti-inflammatory and decreasing pro-inflammatory cytokines [8]. Hypovitaminosis D is observed worldwide and is associated with myopathy, arthralgia, fatigue and paresthesias. And back pain from vitamin D deficiency may be due to myopathy, micro fractures (at vertebral end plate due to hyper-parathyroidism) and Modic changes due to increased susceptibility to inflammation.

Increased incidence of low back pain has also been seen in obese patients which may be due to bio-mechanical causes or accelerated degenerative changes. However, an association of hypovitaminosis $\mathrm{D}$ and obesity with the development of Modic changes in vertebrae is not well described in the literature.

The objectives of this study were: (1) to investigate the levels of vitamin $\mathrm{D}$ in patients with low back pain and study its association with back pain; (2) to study how vitamin D levels were associated with age, gender, BMI; and (3) to evaluate how vitamin D levels and BMI were associated with development of Modic changes in the vertebrae.

\section{Materials and Methods}

\section{Study design}

A cross-sectional cohort study of patients presenting with low back pain at St. John's Medical College was done through non-probability consecutive sampling.

\section{Study population}

Three hundred and sixteen patients who presented to St. John's Medical College, Banglore, during the period of January 2014 to December 2014 with low back pain of more than 6 months duration was selected for the study. Patients in age group 18 to 70 year presenting with low back pain of more than 6 months duration were included in the study. Patients with a specific cause for the pain, like spondylolisthesis, nerve root compression, metastasis, fractures or disc herniation were excluded. Those on vitamin supplements, with metabolic diseases, renal impairment or hepatic dysfunction were also excluded from the study. Pregnant and lactating females were not included. Those who had contraindications for an MRI were also excluded.

\section{Procedure}

The objectives of the study and the procedures were explained to all the participants satisfying the inclusion criteria and they provided written informed consents. A questionnaire was completed by each patient which included age, height, weight, gender, occupation and menstrual history.

Blood samples were drawn from each patient on the same day and serum 25-hydroxy vitamin D levels were analyzed by chemiluminescent assay. Serum levels of more than $30 \mathrm{ng} / \mathrm{dL}$ were considered normal and values between $20 \mathrm{ng} / \mathrm{dL}$ and $30 \mathrm{ng} / \mathrm{dL}$ were considered insufficient. Levels of less than $20 \mathrm{ng} / \mathrm{dL}$ were considered to be deficient. MRI of the lumbar spine was done and assessed by radiologist who also evaluated the Modic changes.

\section{Statistical analysis}

Descriptive data were reported for continuous variables as mean, standard deviation, and range and for categorical variables as frequencies and proportions. Use of nonparametric or parametric statistical method was decided based on distributional graphs. Correlations were investigated using Spearman coefficient for non-normally distributed data and categorical data. For normally distributed and continuous data, Pearson coefficient was applied. Explanatory variables were dichotomised and odds ratios were calculated to investigate the associations between low vitamin D levels and the variables. SPSS ver. 
Table 1. Gender wise distribution of vitamin D levels

\begin{tabular}{lccc} 
& & \multicolumn{2}{c}{ Vitamin D } \\
\cline { 2 - 4 } Gender & $<20 \mathrm{ng} / \mathrm{dL}$ & 21.1 to $30 \mathrm{ng} / \mathrm{dL}$ & $>30 \mathrm{ng} / \mathrm{dL}$ \\
Male & 84 & 38 & 22 \\
Female & 106 & 28 & 38 \\
\hline
\end{tabular}

Table 2. Age wise distribution of vitamin D levels

\begin{tabular}{lccc} 
& \multicolumn{2}{c}{ Vitamin $\mathrm{D}$} \\
\cline { 2 - 4 } Age & $<20 \mathrm{ng} / \mathrm{dL}$ & 21.1 to $30 \mathrm{ng} / \mathrm{dL}$ & $>30 \mathrm{ng} / \mathrm{dL}$ \\
\hline $20 \mathrm{yr}$ & 14 & 6 & 2 \\
$21-40 \mathrm{yr}$ & 96 & 28 & 12 \\
$41-60 \mathrm{yr}$ & 72 & 24 & 32 \\
$>60 \mathrm{yr}$ & 8 & 8 & 14 \\
\hline
\end{tabular}

Table 3. Relationship between vitamin D levels and body mass index

\begin{tabular}{lccc} 
& \multicolumn{2}{c}{ Vitamin D } \\
Body mass index & $<20 \mathrm{ng} / \mathrm{dL}$ & 21.1 to $30 \mathrm{ng} / \mathrm{dL}$ & $>30 \mathrm{ng} / \mathrm{dL}$ \\
\cline { 2 - 4 } & 14 & 14 & 18 \\
$<25 \mathrm{~kg} / \mathrm{m}^{2}$ & 94 & 42 & 26 \\
$25.1-30.0 \mathrm{~kg} / \mathrm{m}^{2}$ & 38 & 46 & 24 \\
$>30.0 \mathrm{~kg} / \mathrm{m}^{2}$ & 38 & \\
\hline
\end{tabular}

16.0 (SPSS Inc., Chicago IL, USA) was used for statistical analysis.

\section{Results}

A total of 316 patients with low back pain participated in the study. The study included 144 males and $172 \mathrm{fe}$ males in the age group 18 to 70 years with mean age being

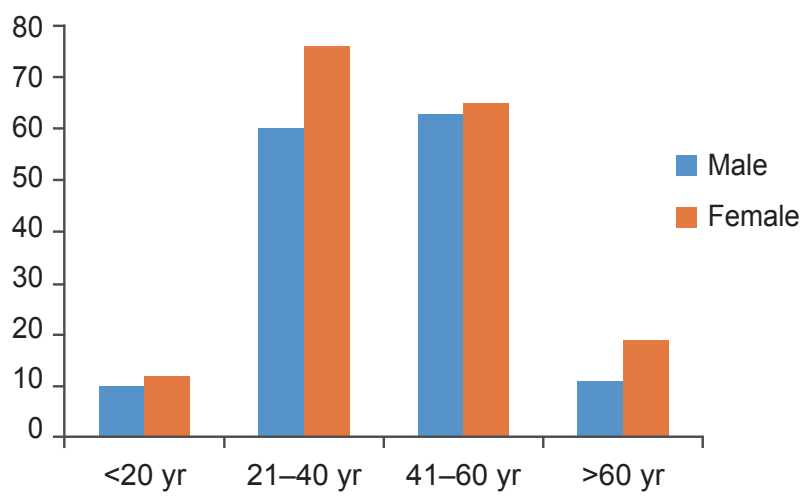

Fig. 1. Age distribution of patients.
$40.9 \pm 14.5$ years (Fig. 1). Vitamin D levels were slightly lower in females (Table 1). The mean BMI was 27.5 \pm 4.5 $\mathrm{kg} / \mathrm{m}^{2}$. Patients with deficient and insufficient vitamin D levels were considered to have low vitamin levels in the analysis. Serum vitamin D levels were almost similar in all age groups (Table 2). Lower vitamin D levels were seen in patients with higher BMI (Table 3). BMI showed significant negative correlation with vitamin D levels (Pearson's coefficient $=-0.68$ ).

Type 1 Modic changes were found in 33\% of the patients, Type 2 in 19\% and both Type 1 and Type 2 changes in 33\% patients (Fig. 2). Statistically significant correlation was found between Modic changes and vitamin D levels (Spearman's rho $=-0.74, p=0.006$ ). Analysis by logistic regression showed higher prevalence of Modic changes in patients with higher BMI (Odds ratio, 2.74; 95\% confidence interval, 1.31 to $5.74, p=0.007$ ) (Table 4 ).

\section{Discussion}

Vitamin D is involved in calcium haemostasis and is 


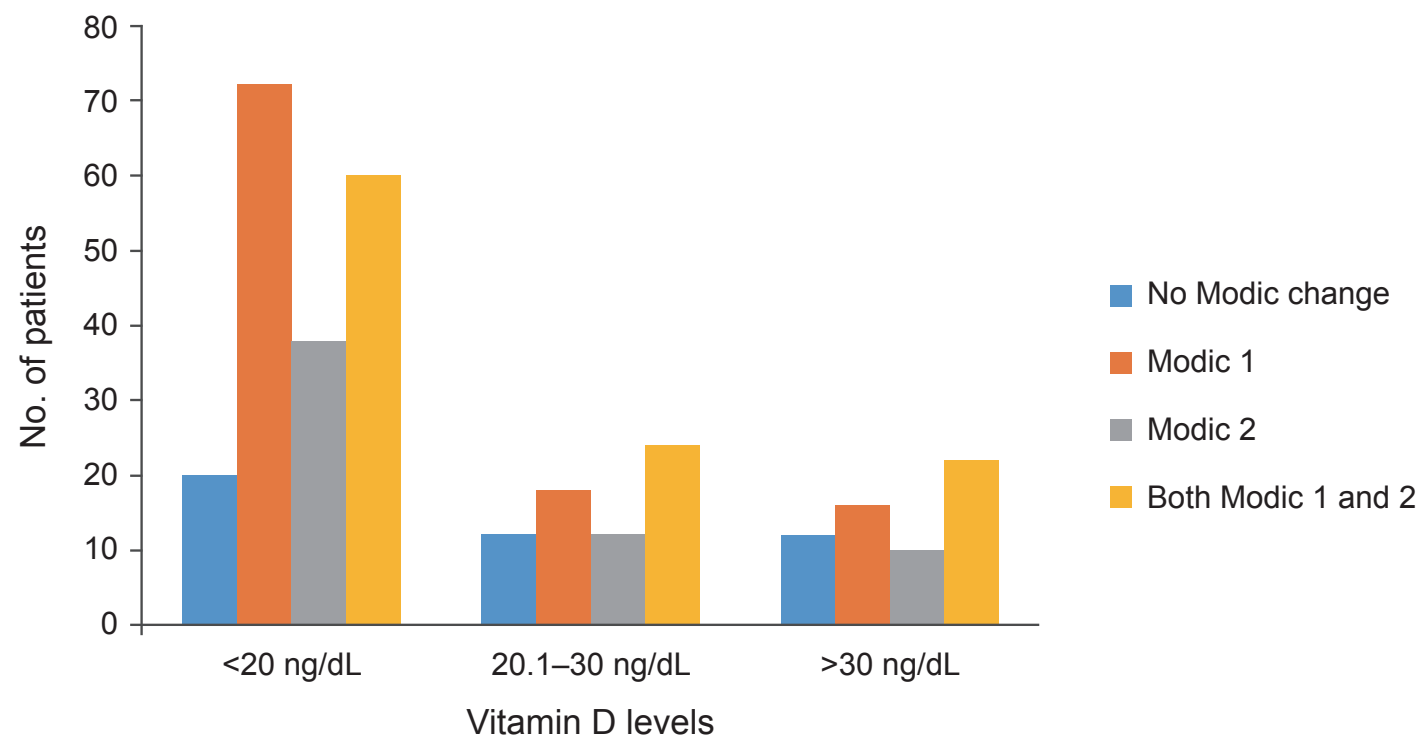

Fig. 2. Association of vitamin D levels with Modic changes.

Table 4. Relationship between Modic changes and body mass index (BMI)

\begin{tabular}{lcc} 
& $\mathrm{BMI} \geq 25 \mathrm{~kg} / \mathrm{m}^{2}$ & $\mathrm{BMl}<25 \mathrm{~kg} / \mathrm{m}^{2}$ \\
Modic changes present & 224 & 48 \\
Modic changes absent & 32 & 12 \\
\hline
\end{tabular}

Odds ratio, 2.7491; 95\% confidence interval, 1.3162-5.7418; z statistic, 2.691; Significance level, $p=0.0071$.

needed for the proper functioning of bones, muscles and nerves. It also has anti-inflammatory properties [8]. Multiple factors like geographical location, sunlight exposure, malnutrition and ethnicity affect the serum levels of vitamin D [9]. The normal serum vitamin D level is still debated $[10,11]$. It is possible that the threshold for development of clinical symptoms differ across different ethnic groups. As vitamin D deficiency has been found to be highly prevalent among sub-tropical Asian population [12], the low levels have been attributed as one of the main causes of higher prevalence of non-specific back pain in that population [13]. However, the prevalence of Modic changes and its correlation with low vitamin D levels in the sub-tropical Asian population has been not well studied.

This study showed that $81 \%$ of the patients with low back pain had low vitamin D levels. The findings were similar to those of Siddique and Malik [14]. Low levels of vitamin $\mathrm{D}$ were reported in patients with musculoskeletal pain by Heidari et al. [15] and McBeth et al. [16]. How- ever for intensity or duration of back pain, no association was found with vitamin D levels in a study conducted by Lotfi et al. [17]. Prevalence of low vitamin D levels in low back pain patients were similar in both genders. As hormonal factors are involved in metabolism of vitamin $\mathrm{D}$ and calcium, lower values of vitamin $\mathrm{D}$ were expected in post-menopausal women but our study showed similar serum values in pre-and post-menopausal age groups. This was in contrast to the study by Lips et al. [18].

Higher BMI was found to be associated with lower vitamin D levels [19]. This has been previously reported in the literature and might be due to storage of vitamin $\mathrm{D}$ in adipose tissue [20,21]. A higher incidence of back pain was seen in patients with high BMI's. The interplay between BMI and vitamin D levels and the role in causation of back pain need to be further investigated. Patients with higher BMI were seen to have higher prevalence of Modic changes on MRI and type 1 changes being more common than type 2 changes (Fig. 3). Increased stress on vertebrae and resulting microfractures may be the reason for these changes.

Modic changes on MRI were more common in patients with low vitamin D levels. Statistically significant correlation was found between low vitamin D levels and development of Modic changes. Type 1 as well as Type 2 changes were seen with increasing frequencies in cases with lower levels of serum vitamin $\mathrm{D}$ and Type 1 changes were more common in this set of patients (Fig. 2). This may be due to increased parathormone leading to increased bone 


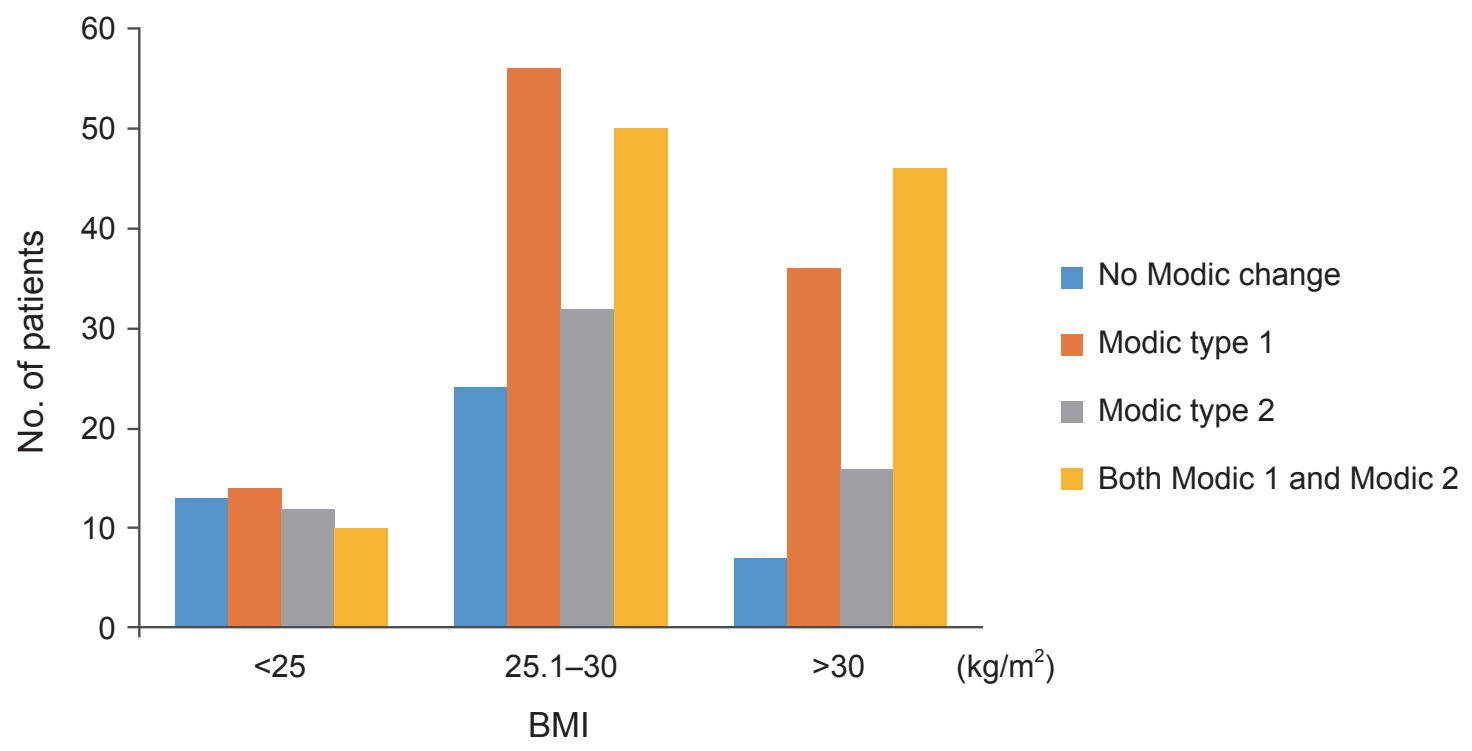

Fig. 3. Association between body mass index (BMI) and Modic changes.

turnover [22] and vertebral micro fractures or due to increased susceptibility to inflammation. Whether vertebral end plates which are composed mainly of hyaline cartilage are susceptible to micro fractures is controversial and further studies need to be performed to address this.

As low back pain is multi-factorial in origin and the factors are interdependent, isolating a single pathologic cause for low back pain is difficult. This study was crosssectional in design and further randomised control trials need to be done to validate its findings. We feel that studies on symptomatic improvement of back pain and potential reversal of Modic changes upon treatment with vitamin D may be warranted.

\section{Conclusions}

Majority of patients with low back pain had vitamin D deficiency. Therefore reduced levels of serum vitamin $\mathrm{D}$ should be considered as a contributing factor for development of low back pain. Patients with Modic changes in MRI were found to have lower serum vitamin D levels but a causal relationship between Modic changes and vitamin $\mathrm{D}$ deficiency needs to be further evaluated.

\section{Conflict of Interest}

No potential conflict of interest relevant to this article was reported.

\section{References}

1. Dionne CE, Dunn KM, Croft PR, et al. A consensus approach toward the standardization of back pain definitions for use in prevalence studies. Spine (Phila Pa 1976) 2008;33:95-103.

2. Waddell G. The back pain revolution. Edinburgh: Churchill Livingstone; 1998.

3. Deyo RA. Diagnostic evaluation of LBP: reaching a specific diagnosis is often impossible. Arch Intern Med 2002;162:1444-7.

4. Modic MT, Steinberg PM, Ross JS, Masaryk TJ, Carter JR. Degenerative disk disease: assessment of changes in vertebral body marrow with MR imaging. Radiology 1988;166:193-9.

5. Jensen TS, Karppinen J, Sorensen JS, Niinimaki J, Leboeuf-Yde C. Vertebral endplate signal changes (Modic change): a systematic literature review of prevalence and association with non-specific low back pain. Eur Spine J 2008;17:1407-22.

6. Albert HB, Kjaer P, Jensen TS, Sorensen JS, Bendix T, Manniche C. Modic changes, possible causes and relation to low back pain. Med Hypotheses 2008;70: 361-8.

7. Holick MF, Chen TC. Vitamin D deficiency: a worldwide problem with health consequences. Am J Clin Nutr 2008;87:1080S-1086S.

8. D’Ambrosio D, Cippitelli M, Cocciolo MG, et al. In- 
hibition of IL-12 production by 1,25-dihydroxyvitamin D3: involvement of NF-kappaB downregulation in transcriptional repression of the p40 gene. J Clin Invest 1998;101:252-62.

9. Arabi A, El Rassi R, El-Hajj Fuleihan G. Hypovitaminosis $\mathrm{D}$ in developing countries-prevalence, risk factors and outcomes. Nat Rev Endocrinol 2010;6: 550-61.

10. Leavitt SB. Vitamin D-a neglected 'analgesic' for chronic musculoskeletal pain [Internet]. Pain Treatment Topics; 2008 [cited 2015 Nov 9]. Available from: http://pain-topics.org.

11. Mosekilde L, Nielsen LR, Larsen ER, Moosgaard B, Heickendorff L. Vitamin D deficiency: definition and prevalence in Denmark. Ugeskr Laeger 2005;167:2933.

12. Akhtar S. Vitamin D status of South Asian populations-risks and opportunities. Crit Rev Food Sci Nutr 2015 Mar 6 [Epub]. http://dx.doi.org./10.1080/10408 398.2013.807419.

13. Sandoughi M, Zakeri Z, Mirhosainee Z, Mohammadi M, Shahbakhsh S. The effect of vitamin D on nonspecific low back pain. Int J Rheum Dis 2013 Oct 14 [Epub]. http://dx.doi.org./10.1111/1756-185x.12172.

14. Siddique SA, Malik YM. Frequency of vitamin D deficiency in patients of low backache. Ann Pak Inst Med Sci 2011;7:208-12.

15. Heidari B, Shirvani JS, Firouzjahi A, Heidari P,
Hajian-Tilaki KO. Association between nonspecific skeletal pain and vitamin D deficiency. Int J Rheum Dis 2010;13:340-6.

16. McBeth J, Pye SR, O’Neill TW, et al. Musculoskeletal pain is associated with very low levels of vitamin $\mathrm{D}$ in men: results from the European Male Ageing Study. Ann Rheum Dis 2010;69:1448-52.

17. Lotfi A, Abdel-Nasser AM, Hamdy A, Omran AA, El-Rehany MA. Hypovitaminosis D in female patients with chronic low back pain. Clin Rheumatol 2007;26:1895-901.

18. Lips P, Chapuy MC, Dawson-Hughes B, Pols HA, Holick MF. An international comparison of serum 25-hydroxyvitamin D measurements. Osteoporos Int 1999;9:394-7.

19. Vimaleswaran KS, Berry DJ, Lu C, et al. Causal relationship between obesity and vitamin $\mathrm{D}$ status: bidirectional Mendelian randomization analysis of multiple cohorts. PLoS Med 2013;10:e1001383.

20. Wortsman J, Matsuoka LY, Chen TC, Lu Z, Holick MF. Decreased bioavailability of vitamin D in obesity. Am J Clin Nutr 2000;72:690-3.

21. Drincic AT, Armas LA, Van Diest EE, Heaney RP. Volumetric dilution, rather than sequestration best explains the low vitamin D status of obesity. Obesity (Silver Spring) 2012;20:1444-8.

22. Mosekilde L. Primary hyperparathyroidism and the skeleton. Clin Endocrinol (Oxf) 2008;69:1-19. 